\title{
Application of tension-free hernioplasty with hernia meshes of different materials and the postoperative effects on the reproductive function of male rats
}

\author{
HAO XU, MING CHEN, QIANRU XU, ZHENLONG WANG and ZHIDONG QIU \\ Department of Hepatobiliary Surgery, Affiliated Hospital of Guangdong Medical College, \\ Xiashan, Zhanjiang 524001, P.R. China
}

Received June 25, 2013; Accepted February 10, 2014

DOI: $10.3892 / \mathrm{mmr} .2014 .2014$

\begin{abstract}
This study aimed to compare the effects of polypropylene (PP), lightweight PP (UP) and expanded polytetrafluorethylene (e-PTFE) hernia mesh on the reproductive function of adult male Sprague-Dawley (SD) rats following open tension-free hernioplasty. Forty adult SD rats were obtained and divided into five groups: A sham-operated (FO) group, an e-PTFE mesh group, a PP mesh group, the UP mesh group and a normal control (NC) group (without any surgical manipulation). Ninety days following open tension-free hernioplasty, hematoxylin and eosin staining and immunhistochemistry were used to observe the pathological changes of the testicular tissue and to compare the expression of hypoxia-inducible factor- $1 \alpha$ (HIF-1 $\alpha$ ) in the rat testis, respectively. ELISA was used to analyze the serum concentration of antisperm antibodies (AsAbs) and routine semen testing was conducted to measure the percentage of grade $a+b$ sperm from the epididymis. More than $50 \%$ of mesh adherence to the spermatic cord was observed in the PP and UP groups, and mild or no adhesion was observed in the NC, FO and e-PTFE groups. In the UP and PP groups, marked congestion of necrotic tissue was observed in the seminiferous tubule cavity, a significant reduction in the percentage of grade $a+b$ sperm and a significant increase in the expression levels of AsAbs and HIF- $\alpha$. It was concluded that the e-PTFE mesh exhibited a marginal effect on the reproductive function of rats compared with that of the PP and UP mesh and is more suitable for tension-free hernioplasty. The clinical significance of these results requires further elucidation with a multi-centered prospective study.
\end{abstract}

Correspondence to: Professor Ming Chen, Department of Hepatobiliary Surgery, Affiliated Hospital of Guangdong Medical College, 57 Renmin Street, Xiashan, Zhanjiang 524001, P.R. China E-mail: cm641211@126.com

Key words: inguinal hernia, hernia mesh, tension-free hernioplasty, reproductive function, infertility

\section{Introduction}

Inguinal hernia is the most common type of hernia (1). The development of novel biological materials has led to a change in the therapeutic strategies for inguinal hernia $(2,3)$. Open tension-free hernia surgery with applied mesh has decreased the recurrence rate of inguinal hernias and reduced the rehabilitation period compared with that of sutured repairs (4). Several different tension-free techniques have been developed and the use of mesh has become increasingly common (5).

However, all hernioplasty techniques may present postoperative complications associated with the scrotum and testis, including hematomas, atrophy, sterility, tumefaction, ecchymosis and hydrocele (6-8). Previous studies have shown that the use of open tension-free hernioplasty with mesh is correlated with spermatogenesis reduction and infertility $(9,10)$. Furthermore, the increase of hernia correction by means of prosthesis and the interest in fertility later in life, added to the fact that the mesh (foreign body) provokes a strong fibroblastic reaction in the cicatrisation process of the posterior wall of the inguinal canal whose effects on the structures and function of the spermatic funiculus, epididium and testis are well known (11).

A previous study conducted in the United States of America found that tension-free repair of inguinal hernias resulted in infertility after $0.5-3$ years with vas deferens blockage. It was proposed that it was correlated with the application of polypropylene (PP) mesh (12). Peiper et al (13) compared tension-free hernia repair to the traditional method using pig and rabbit experimental animal models. It was demonstrated that following hernia repair, spermatic artery perfusion decreased and spermatic vein thrombosis occurred in one-third of pigs, while the traditional method induced no abnormal symptoms indicating that spermatic vein thrombosis was closely associated with mesh implantation. Furthermore, LeBlanc et al (14) found implanted mesh can cause testicular venous congestion. The interaction between the spermatic cord and hernia mesh can impact the structure of the inguinal canal and sperm quality.

Hypoxia-inducible factor- $1 \alpha$ (HIF-1 $\alpha$ ) is widely involved in adaptive responses to hypoxia in mammalian cells. It is an important regulatory factor involved in blood supply, oxidation 
and energy metabolism (15). As the mesh applied in (endoscopic application) inguinal hernia repair is placed close to the vas deferens and spermatic vessels, the mesh-induced inflammatory reaction may lead to dysfunction of these structures. Therefore, HIF-1 $\alpha$ expression was examined to determine the effects of hernia mesh application.

A previous study identified that serum antisperm antibodies (AsAbs) were found in patients following vasectomy, and in monkeys a correlation between granuloma formation and the development of sperm autoantibodies after vasectomy has been reported (16). In addition, researchers have demonstrated that tension-free hernia repair can lead to occlusion of the vas deferens and sperm granuloma formation (17); however, whether the pathological changes result in an autoimmune reaction have not been fully elucidated.

In the present study, hernia meshes of different materials were applied, including heavy PP, expanded polytetrafluoroethylene (e-PTFE) and lightweight PP (UP) meshes, into adult male Spague-Dawley rats to examine the effects on spermatic structure, testicular structure, semen change, the number of spermatogenic cells, HIF-1 $\alpha$ expression levels and serum concentration of AsAbs. This study aimed to compare the hernia meshes of different materials in order to determine the most appropriate application and a theoretical basis for reducing the negative effects of hernia mesh on the reproductive function.

\section{Materials and methods}

Experimental animals and meshes. Forty male Sprague-Dawley rats (Rattus norvegicus) (age, 90 days; weight, 300-320 g) were obtained from the Experimental Animal Center of Guangdong Medical College (Zhanjiang, China). The animals were housed in a colony room under a $12 / 12 \mathrm{~h}$ light/dark cycle at $21 \pm 2^{\circ} \mathrm{C}$ and had free access to water and a complete diet ad libitum. The animals were randomly divided into five groups as follows: The normal control (NC) group, the sham-operated (FO) group, the e-PTFE mesh group, the PP mesh group and the UP mesh group. The PP, UP and e-PTFE meshes were purchased from C.R. Bard, Inc. (MarlexH; St. Louis, MO, USA), Ethicon, Inc. (Ultrapro; Amersfoort, The Netherlands) and W.L. Gore \& Associates, Inc. (Flagstaff, AZ, USA), respectively. The PP mesh is a monofilament, non-absorbable, inert, sterile and porous mesh with a thickness of $\sim 0.44 \mathrm{~mm}$. The UP mesh is partially absorbable with 3-4-mm pores consisting of non-absorbable PP filaments and polyglactin filaments absorbed by hydrolysis. The e-PTFE mesh is a 1-mm thick mesh made from strong, soft inert and conformable e-PTFE with a structure that ensures early fixation to the host tissue with minimal foreign body reaction. This study conformed with the Guide for the Care and Use of Laboratory Animals published by the USA National Institutes of Health (NIH Publication no. 85-23, Revised 1985), and has been approved by the Animal Care and Use Committee of Guangdong Medical College (Xiashan, China).

Surgical procedure. The rats were anesthetized by intraperitoneal injection of ketamine hydrochloride $(50 \mathrm{mg} / \mathrm{kg})$ and xylazine $(10 \mathrm{mg} / \mathrm{kg})$. The skin was shaved and disinfected with povidone-iodine. The three different meshes (PP, UP and e-PTFE) were inserted surrounding the vas deferens and spermatic vessels with a 4-0 nonabsorbable silk fixed needle. The skin was closed using a nylon 4.0 needle in a continuous suture. The FO group was established by the simple closure of the midline laparatomy by continuous nylon 4.0 sutures. The $\mathrm{NC}$ group received no surgery. All animals were sacrificed by the method of air embolism according to the requirements of the Guangdong Medical Experimental Animal Center 90 days after mesh implantation. During the 90 day observation period all animals were observed daily to assess local and systemic (wound)-complications.

Postoperative observations. The adhesion formation was evaluated by the classification of adhesions as loose, firmly attached or integrated. Quantification was performed by determining the surface area of each prosthesis covered by adhesions as previously described (18). The spermatic cord tissue located on the side of implanted mesh was obtained and fixed in $4 \%$ neutral formalin solution for $24 \mathrm{~h}$. Tissues were embedded in paraffin for hematoxylin and eosin staining to observe the pathological changes in the inner diameter thickness and cross-sectional area of the vas deferens, and to grade the spermatogenic cells in the cross-sectional areas of individual tissue slices using the Johnsen score method (19).

Percentage of spermatogenic cells. Enzymatic digestion of testicular tissue was performed. Briefly, the tissue was divided into small pieces and washed three times in D-Hank's solution (Senbeijia, Nanjing, China) to eliminate blood cells. Tissue was minced using ophthalmic scissors (Stronger Medical Instrument Co., Ltd., Suzhou, China) until a semi-liquid state was achieved. Following the addition of $0.25 \%$ trypsin (50-fold the amount of tissue), tissues were transferred into a small glass flask and digested for $30 \mathrm{~min}$ at $37^{\circ} \mathrm{C}$. Trypsin was then removed and the suspension was washed three times with D-Hank's solution at $560 \mathrm{x}$ g for $5 \mathrm{~min}$. Collagenase $(0.1 \%)$ was added and incubated for $30 \mathrm{~min}$ under similar conditions. The cell suspension was centrifuged and pelleted cells were resuspended in D-Hank's solution and propidium iodide nucleic acid was added to stain for $30 \mathrm{~min}$. The cells were then analyzed using flow cytometry (FACSCanto II flow cytometer; BD Biosciences, Shanghai, China).

Sperm motility detection. The epididymis located on the side of implanted mesh was removed and washed three times with Dulbecco's phosphate-buffered saline (D-PBS) to remove surface blood. It was then placed in a sterile petri dish with $5 \mathrm{ml}$ of preheated $\left(37^{\circ} \mathrm{C}\right) \mathrm{D}-\mathrm{PBS}$. Deep, longitudinal sections were sheared with ophthalmic scissors from the tail of the epididymis and placed in an incubator at $37^{\circ} \mathrm{C}$ for $10 \mathrm{~min}$, then $20 \mathrm{ml}$ sperm suspension was pipetted onto a clean, prewarmed sperm counter (Huafang Shenhuo Technology Co., Ltd., Beijing, China). Motility parameters were measured with an automatic sperm analyzer (Hamilton Thorn Motility Analyzer, version 7.2; Hamilton Thorne Research, Beverly, MA, USA). At least five widely spaced fields were examined to provide an estimated percentage of motile cells. The sperm motility was evaluated using the WHO classification system (WHO, 1999), with grades a (rapid progressive or linear motility), b (slow progressive or curvilinear motility), c (not progressive or in loco motility) and d (absent motility) (20). 
Table I. Degree of adhesion between different hernia meshes and the spermatic cord.

\begin{tabular}{lcl}
\hline Group & $\begin{array}{c}\text { No. of } \\
\text { cases }\end{array}$ & $\begin{array}{l}\text { Degree of } \\
\text { adhesion }\end{array}$ \\
\hline NC & 8 & $0.0(0.0)$ \\
FO & 8 & $0.5(0.0-1.0)$ \\
e-PTFE & 8 & $1.0(0.0-1.0)^{\mathrm{a}}$ \\
PP & 8 & $3.0(2.5-3.0)^{\mathrm{a}}$ \\
UP & 8 & $2.5(2.0-3.0)^{\mathrm{a}}$ \\
\hline
\end{tabular}

${ }^{\mathrm{a}} \mathrm{P}<0.05$, compared with the $\mathrm{FO}$ group. $\mathrm{NC}$, the normal group; $\mathrm{FO}$, the sham-operated group; e-PTFE, the test group which received expanded polytetrafluorethylene mesh; PP, the test group which received polypropylene mesh; UP, the test group which received lightweight PP mesh.

Table II. Grade of spermatogenic cells in each group.

\begin{tabular}{lcc}
\hline Group & $\begin{array}{c}\text { No. of } \\
\text { cases }\end{array}$ & $\begin{array}{c}\text { Scoring of } \\
\text { spermatogenic cell }\end{array}$ \\
\hline NC & 8 & $10.0(9.0-10.0)$ \\
FO & 8 & $9.0(9.0-10.0)^{\mathrm{a}}$ \\
e-PTFE & 8 & $9.0(9.0-10.0)^{\mathrm{a}, \mathrm{b}}$ \\
PP & 8 & $8.0(7.0-9.0)^{\mathrm{a}, \mathrm{b}}$ \\
UP & 8 & $8.0(8.0-9.0)^{\mathrm{a}, \mathrm{b}}$ \\
\hline
\end{tabular}

${ }^{\mathrm{a}} \mathrm{P}<0.05$ compared with the $\mathrm{NC}$ group; ${ }^{\text {b }}<0.05$ compared with the FO group. NC, the normal group; FO, the sham-operated group; e-PTFE, the test group which received the expanded polytetrafluorethylene mesh; PP, the test group which received the polypropylene meshes; UP, the test group which received the lightweight PP mesh.

Immunohistochemistry (IHC) of HIF-1 $\alpha$ in testicular tissue. IHC was performed according to the methods described previously. The tissue sections were pretreated, heated, blocked and incubated with polyclonal rabbit anti-human HIF-1 $\alpha$ (clone H-206; Santa Cruz Biotechnology, Inc., Santa Cruz, CA, USA). Negative controls, in which the primary antibody was substituted with antibody diluent (Yajikit, Shanghai, China) were also analyzed. The sections were imaged with a Nikon Eclipse 55i microscope equipped with a Nikon DS-5M camera (Nikon, Tokyo, Japan), using Image-Pro Plus acquisition software. Staining intensity was assessed and five random fields of each slide were analyzed with Image-Pro Plus 6.0 (Media Cybernetics, Rockville, MD, USA) to calculate the mean optical density analysis value (mean IOD).

ELISA to measure AsAb concentration. Venous blood of 4-5 $\mathrm{ml}$ was obtained from the rats chest and centrifuged at $560 \mathrm{x} \mathrm{g}$ for $5 \mathrm{~min}$. The supernatant was collected in $1.5 \mathrm{ml}$ eppendorf tubes and stored at $-20^{\circ} \mathrm{C}$ prior to analysis. Using ELISA, microtiter plates were coated with equal quantities of the serum sample $(50 \mu \mathrm{g})$ in each well and the standard protocol of ELISA was followed using primary mouse anti-human
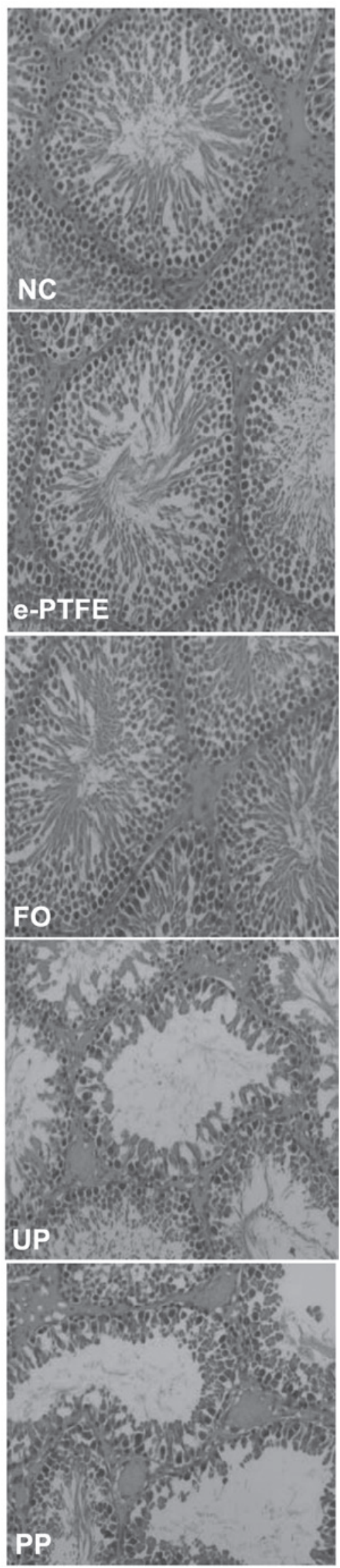

Figure 1. Hematoxylin and eosin staining of the testicular tissues (magnification, $\mathrm{x} 200$ ). NC, the normal group; FO, the sham-operated group; PP, the test group which received polypropylene mesh; e-PTFE, the test group which received expanded polytetrafluorethylene mesh; UP, the test group which received lightweight PP mesh. 

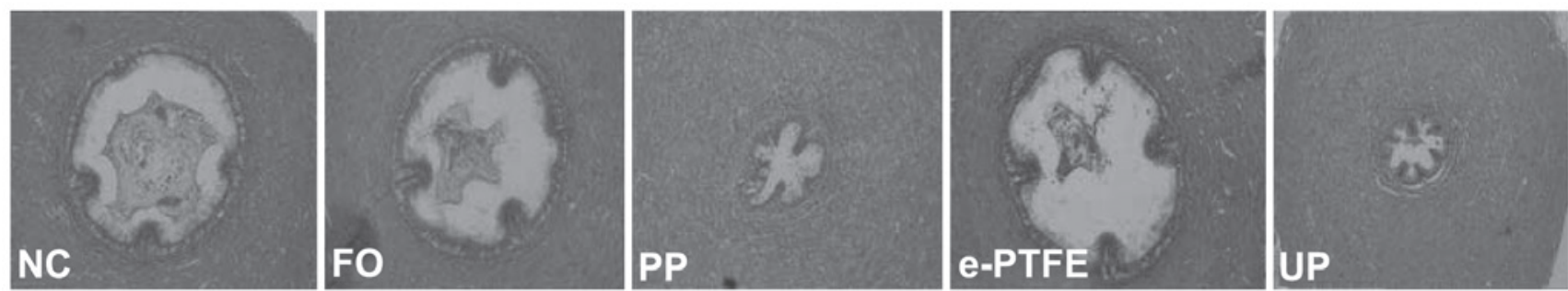

Figure 2. Pathological changes in the vas deferens. NC, the normal group; FO, the sham-operated group; PP, the test group which received polypropylene mesh; e-PTFE, the test group which received expanded polytetrafluorethylene mesh; UP, the test group which received the lightweight PP mesh.

AsAb monoclonal $\mathrm{IgG}$ and secondary alkaline phosphatase conjugated goat anti-mouse IgG (Chemicon, Temecula, CA, USA). The results were measured at $405 \mathrm{~nm}$ using an ELISA reader (Quanta Biotech, Surrey, UK). Standard curves for each of the substances analyzed were included.

Statistical analysis. The measurement data were compared by one-way analysis of variance. A least significant difference test (t-test) was used to compare the mean values between groups. If the data did not meet the normality and homogeneity, the Kruskal-Wallis rank sum test was used. All data were analyzed using SPSS software, version 16.0 (SPSS, Inc., Chicago, IL, USA). $\mathrm{P}<0.05$ was considered to indicate a statistically significant difference.

\section{Results}

General observations. The breathing and heart rate of the rats in each group, and recovering activity, including drinking and eating, were normal $6 \mathrm{~h}$ after surgery. There were two cases of wound infection in the PP and e-PTFE groups, respectively; however, infection was decreased seven days after treatment with iodophor disinfectant and the mesh was not removed. No subcutaneous hematoma, effusion and empyema were observed in each group. There were no fatalities during this experiment.

Hernia meshes and spermatic cord adhesion. Adhesions were graded according to an adhesion scoring system (grade 0-3). No adhesions were observed in the NC group and mild adhesions were identified in the groin area of the FO group. Spermatic cord adhesions in the FO and e-PTFE groups were thin and filmy. The adhesion area in the e-PTFE group was $<25 \%$ with a mean score of 1.0 at 3 months $(\mathrm{P}<0.05$ compared with the FO group). Adhesions in the UP group were dense at 3 months and the adhesion area was $>50 \%$ with a mean adhesion score of 2.5. However, adhesions in the PP group were more dense and extensive, having a mean score of $3(\mathrm{P}<0.05$ compared with the FO group) and an adhesion area of $>50 \%$ (Table I).

Testicular pathological changes and spermatogenic cell classification. Histological analysis demonstrated that the process of spermatogenesis was normal in the NC group with increased layers of spermatogenic cells, higher sperm count, and fewer lumen of the seminiferous tubules were obstructed by necrotic tissue. The FO and e-PTFE groups were similar to the NC group, but a low sperm count and less seminiferous tubules were observed. However, in the PP and UP groups, an abnormal spermatogenesis process with disordered seminiferous tubules,
Table III. Sperm percentage of $a+b$ motile forms in each group.

\begin{tabular}{lcc}
\hline Group & $\begin{array}{c}\text { No. of } \\
\text { cases }\end{array}$ & Grade $\mathrm{a}+\mathrm{b}$ sperm $(\%)$ \\
\hline NC & 8 & $80.32 \pm 4.33$ \\
FO & 8 & $69.83 \pm 8.83^{\mathrm{a}}$ \\
e-PTFE & 8 & $63.90 \pm 6.23^{\mathrm{a}, \mathrm{b}}$ \\
PP & 8 & $37.25 \pm 11.54^{\mathrm{c}-\mathrm{d}}$ \\
UP & 8 & $37.97 \pm 10.24^{\mathrm{c}-\mathrm{f}}$ \\
\hline
\end{tabular}

${ }^{\text {a }}>0.05$ compared with the $\mathrm{NC}$ group; ${ }^{\mathrm{b}} \mathrm{P}>0.05$ compared with the FO group; ${ }^{\mathrm{P}}<0.05$ compared with the $\mathrm{NC}$ group; ${ }^{\mathrm{d}} \mathrm{P}<0.05$ compared with the FO group; ${ }^{\mathrm{e}} \mathrm{P}<0.05$ compared with the e-PTFE group; ${ }^{\mathrm{f}} \mathrm{P}>0.05$ compared with the $\mathrm{PP}$ group. $\mathrm{NC}$, the normal group; FO, the sham-operated group; e-PTFE, the test group which received expanded polytetrafluorethylene mesh; PP, the test group which received polypropylene mesh; UP, the test group which received lightweight PP mesh.

damaged germinal epithelium and reduced spermatogenic cell layers was detected. A large number of sperm cells were observed; however, few sperm were observed in the seminiferous tubules and a section of the seminiferous tubule cavity was congested by necrotic tissue (Fig. 1). Therefore, the Johnsen score method was used to obtain the grade of spermatogenic cells in each group (Table II).

Influence of the different meshes on sperm motility. The influence of PP, UP and e-PTFE meshes on sperm motility was evaluated using the WHO classification system (WHO, 1999) by calculating the percentage of sperm with motility of grades $a+b$. The percentage of sperm with motility of grades $c+d$ was eliminated due to the presence of apoptotic and necrotic spermatozoa. Ninety days after surgery, no significant difference was observed in the percentage of grade $a+b$ sperm in the FO and e-PTFE groups compared with that of the NC group $(\mathrm{P}>0.05)$. While the percentage of sperm with $\mathrm{a}+\mathrm{b}$ grade motility significantly decreased compared with that of the $\mathrm{NC}$ and FO groups $(\mathrm{P}<0.05)$. The percentage of sperm with grade $a+b$ motile forms are shown in Table III.

Spermatogenic cells detected by flow cytometry. As C-values refer to the DNA content and ploidy refers to the number of chromosomes, the detected cells were classified as spermatogonia (2C), diploid primary spermatocytes (4C) and haploid 
Table IV. Percentage of the different populations of spermatogenic cells (mean \pm standard deviation).

\begin{tabular}{lcccc}
\hline Group & $\begin{array}{c}\text { No. of } \\
\text { cases }\end{array}$ & $1 \mathrm{C}$ & $2 \mathrm{C}$ & $4 \mathrm{C}$ \\
\hline NC & 8 & $56.66 \pm 5.59$ & $24.09 \pm 4.97$ & $16.25 \pm 3.51$ \\
FO & 8 & $58.25 \pm 4.05^{\mathrm{a}}$ & $24.09 \pm 3.58^{\mathrm{a}}$ & $17.66 \pm 2.83^{\mathrm{a}}$ \\
e-PTFE & 8 & $56.85 \pm 4.22^{\mathrm{a}, \mathrm{b}}$ & $23.95 \pm 4.08^{\mathrm{a}, \mathrm{b}}$ & $19.20 \pm 3.95^{\mathrm{a}, \mathrm{b}}$ \\
PP & 8 & $45.26 \pm 4.01^{\mathrm{b}, \mathrm{d}}$ & $29.49 \pm 3.56^{\mathrm{b}, \mathrm{d}, \mathrm{e}}$ & $25.25 \pm 3.03^{\mathrm{b}, \mathrm{d}, \mathrm{e}}$ \\
UP & 8 & $44.08 \pm 5.00^{\mathrm{b}, \mathrm{d}-\mathrm{f}}$ & $30.26 \pm 4.16^{\mathrm{b}, \mathrm{d}-\mathrm{f}}$ & $25.66 \pm 3.04^{\mathrm{b}, \mathrm{d}-\mathrm{f}}$ \\
\hline
\end{tabular}

${ }^{\mathrm{a}} \mathrm{P}>0.05$ compared with the $\mathrm{NC}$ group; ${ }^{\mathrm{b}} \mathrm{P}<0.05$ compared with the $\mathrm{NC}$ group; ${ }^{\mathrm{C}} \mathrm{P}>0.05$ compared with the FO group; ${ }^{\mathrm{d}} \mathrm{P}<0.05$ compared with the FO group; ${ }^{\mathrm{e}} \mathrm{P}<0.05$ compared with the e-PTFE group; ${ }^{\mathrm{f}} \mathrm{P}>0.05$ compared with the PP group. NC, the normal group; FO, the sham-operated group; e-PTFE, the test group which received expanded polytetrafluorethylene mesh; PP, the test group which received polypropylene mesh; UP, the test group which received lightweight PP mesh. 1C, haploid round spermatids; $2 \mathrm{C}$, spermatogonia; $4 \mathrm{C}$, diploid primary spermatocytes.

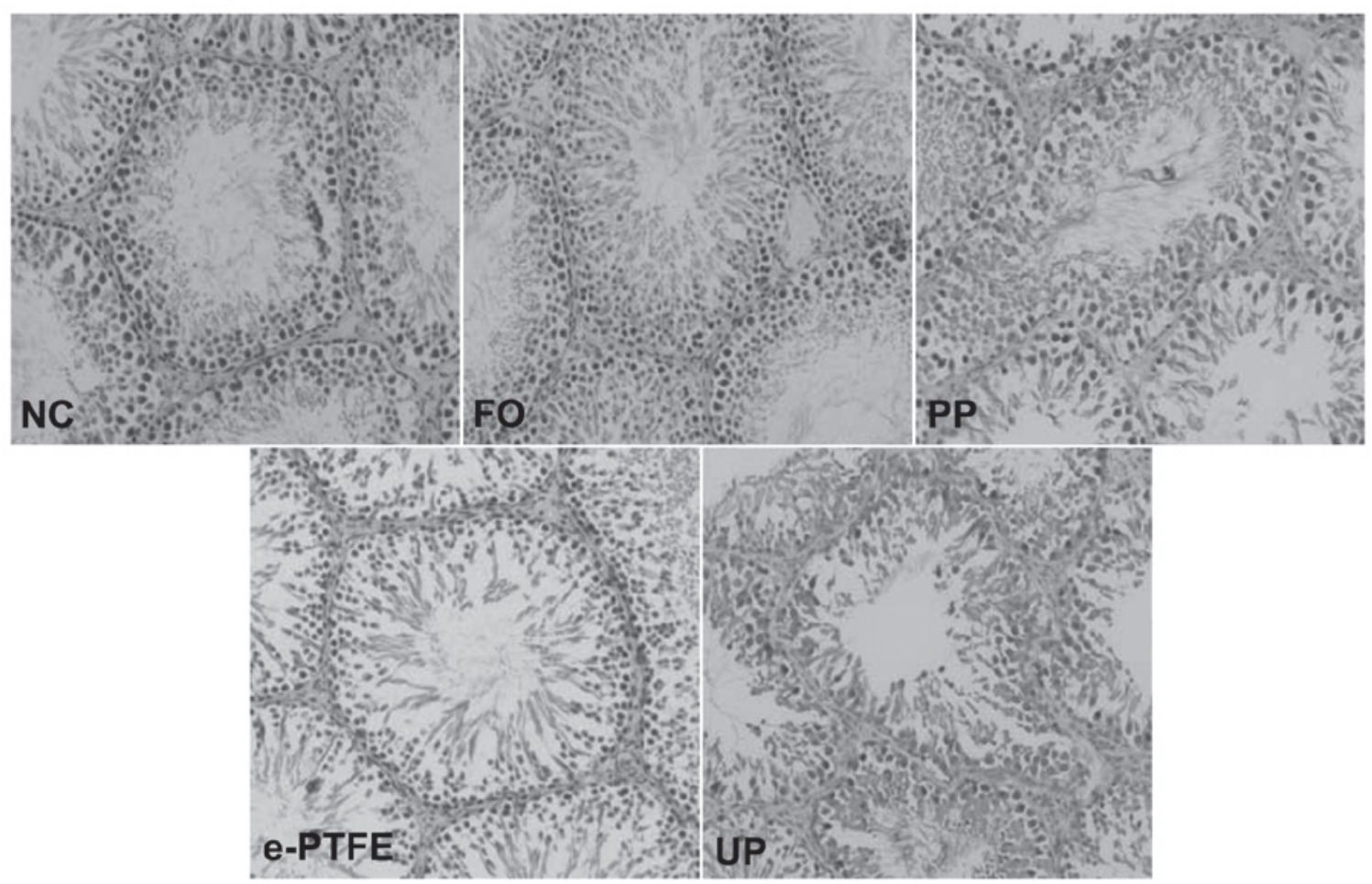

Figure 3. Immunohistochemistry shows HIF-1 $\alpha$ expression in the testicular tissues. (staining, hematoxylin and eosin; magnification, x200). NC, the normal group; FO, the sham-operated group; PP, the test group which received polypropylene mesh; e-PTFE, the test group which received expanded polytetrafluorethylene mesh; UP, the test group which received lightweight PP mesh. HIF-1 $\alpha$, hypoxia-inducible factor-1 $\alpha$.

round spermatids (1C). Flow cytometry was used to analyze the testicular germ cell population in rats. As shown in Table IV, the difference in the percentage of spermatogenic cells between the FO, e-PTFE and NC groups were not statistically significant $(\mathrm{P}>0.05)$. The number of $1 \mathrm{C}$ cells were significantly reduced in the PP and UP groups, while the $2 \mathrm{C}$ and $4 \mathrm{C}$ cells markedly increased compared with that of the $\mathrm{NC}, \mathrm{FO}$ and e-PTFE groups.

Pathological changes in the vas deferens. The crosssectional area of the vas deferens showed that the mucous membranes of the NC group were complete and smooth, the lumen was unobstructed and sperm were detected in the cavity. The FO and e-PTFE groups showed no significant changes compared with the NC group. By contrast, the mucous membrane in the cross-sectional area of the lumen in the PP and UP groups was significantly reduced. The mucous membrane was disordered, sparse or even absent (Fig. 2).

HIF-1 $\alpha$ expression in testicular tissue. To determine whether mesh affects the expression of HIF-1 $\alpha$ in the testis, IHC was performed and the mean IOD was calculated. The expression of HIF-1 $\alpha$ in the NC and FO groups was at a minimal level $(0.0023 \pm 0.0006$ and $0.0026 \pm 0.0007$, respectively). Although the expression in the e-PTFE group showed a marginal increase, the difference was not statistically significant compared with the NC and FO groups. However, the expression levels of 
Table V. Expression levels of HIF-1 $\alpha$ in testicular tissue of each group (mean \pm standard deviation).

\begin{tabular}{lcl}
\hline Group & $\begin{array}{c}\text { No. of } \\
\text { cases }\end{array}$ & HIF-1 $\alpha$ expression \\
\hline NC & 8 & $0.0023 \pm 0.0006$ \\
FO & 8 & $0.0026 \pm 0.0007^{\mathrm{a}}$ \\
e-PTFE & 8 & $0.0042 \pm 0.0027^{\mathrm{a}, \mathrm{c}}$ \\
PP & 8 & $0.0858 \pm 0.0209^{\mathrm{b}, \mathrm{d}, \mathrm{e}}$ \\
UP & 8 & $0.0936 \pm 0.0123^{\mathrm{b}, \mathrm{d}-\mathrm{f}}$ \\
\hline
\end{tabular}

${ }^{a} \mathrm{P}>0.05$ compared with the $\mathrm{NC}$ group; ${ }^{\text {}} \mathrm{P}<0.05$ compared with the $\mathrm{NC}$ group; ${ }^{\mathrm{C}} \mathrm{P}>0.05$ compared with the $\mathrm{FO}$ group; ${ }^{\mathrm{d}} \mathrm{P}<0.05$ compared with the FO group; ${ }^{\mathrm{e}} \mathrm{P}<0.05$ compared with the e-PTFE group; ${ }^{\mathrm{f}} \mathrm{P}<0.05$ compared with the $\mathrm{PP}$ group. $\mathrm{NC}$, the normal group; FO, the sham-operated group; e-PTFE, the test group which received expanded polytetrafluorethylene mesh; PP, the test group which received polypropylene mesh; UP, the test group which received lightweight PP mesh.

Table VI. AsAb concentration in the serum of each group (mean \pm standard deviation).

\begin{tabular}{lcc}
\hline Group & $\begin{array}{c}\text { No. of } \\
\text { cases }\end{array}$ & AsAb (pg/ml) \\
\hline NC & 8 & $1.67 \pm 1.97$ \\
FO & 8 & $6.81 \pm 3.44^{\mathrm{a}}$ \\
e-PTFE & 8 & $7.50 \pm 3.67^{\mathrm{a}, \mathrm{c}}$ \\
PP & 8 & $114.72 \pm 11.57^{\mathrm{b}, \mathrm{d}, \mathrm{e}}$ \\
UP & 8 & $74.58 \pm 9.22^{\mathrm{b}, \mathrm{d}-\mathrm{f}}$ \\
\hline
\end{tabular}

${ }^{a} \mathrm{P}>0.05$ compared with the $\mathrm{NC}$ group; ${ }^{\mathrm{b}} \mathrm{P}<0.05$ compared with the $\mathrm{NC}$ group; ${ }^{\mathrm{P}}>0.05$ compared with the $\mathrm{FO}$ group; ${ }^{\mathrm{d}} \mathrm{P}<0.05$ compared with the FO group; ${ }^{\mathrm{P}} \mathrm{P}<0.05$ compared with the e-PTFE group; ${ }^{\mathrm{P}}<0.05$ compared with PP group. NC, the normal group; FO, the sham-operated group; e-PTFE, the test group which received expanded polytetrafluorethylene mesh; PP, the test group which received polypropylene mesh; UP, the test group which received lightweight PP mesh.

HIF-1 $\alpha$ in the PP and UP groups were significantly augmented (Table V and Fig. 3).

AsAb detection in the rat serum. The AsAb concentration in the NC group was expressed at a minimal level. No statistically significant difference was identified between the FO, e-PTFE and $\mathrm{NC}$ groups $(\mathrm{P}>0.05)$. Compared with the $\mathrm{NC}, \mathrm{FO}$ and e-PTFE groups, the concentration of AsAbs was significantly increased and the differences were statistically significant in the PP and UP groups $(\mathrm{P}<0.05)$ (Table VI).

\section{Discussion}

At present, the incidence of male inguinal hernia is $\sim 3 \%$ (21). In 1989, Lichtenstein was the first to introduce the concept of tension-free hernia repair with PP mesh and demonstrated its advantages, including low recurrence and infection rates $(22,23)$. In the past few decades, the method of tension-free hernioplasty with PP mesh has gradually been accepted by the majority of surgeons and the number of applications is rapidly increasing.

Several studies have focused on the effects of tension-free inguinal hernia repair in patients, particularly in China (24). These studies have shown excellent results with indices of low recidivism. Similar to other surgical procedures, complications are always a risk factor that must be considered. The application of hernia mesh to repair inguinal hernia may induce long-term tissue reactions depending on the type of mesh and location, and may be considered an etiological factor, although the specific causes of tissue reaction remain unknown. Considering the high incidence of inguinal hernia repairs among male patients examined at infertility clinics, rats were selected as models of inguinal hernia as their inguinal region is similar to that of humans.

In this study, meshes of different materials (e-PTFE, PP and UP) were used for hernia surgery. There was one case of wound infection observed in the PP and e-PTFE groups; however, administration of iodophor disinfectant healed the wound infection after seven days and prevented mortality. The macroporous biomaterials, PP and UP, induced a higher degree of adhesion formation. By contrast, the expanded e-PTFE mesh achieved total integration with newly formed surrounding tissue and increased the resistance to adhesions with the spermatic cord. Furthermore, e-PTFE did not cause significant changes to the vas deferens, testicular tissue and $\mathrm{As} \mathrm{Ab}$ concentration; therefore, demonstrating effective protection of testicular function. In the PP and UP groups, the pathological changes between adherence with mesh in the spermatic funiculus was detected in all the animals, including the jeopardizing of the deferent duct. Similar aspects were also found in other studies $(6,25)$. The reduction of the lumen of the deferent duct on the mesh side could also be induced by application of the PP and UP mesh.

HIF- $\alpha$ expression levels were significantly increased in the PP and UP groups compared with the FO group. In addition, basement membrane distortions in the rats seminiferous tubule, disordered germinal epithelial and reduced spermatogenic cell layers with rare sperms were observed in the PP and UP groups. Flow cytometry also confirmed a decrease in the total number of germ cells with reduced $1 \mathrm{C}$ and increased 4C. As HIF- $\alpha$ is a vital regulatory factor associated with the blood supply, oxidation, energy metabolism and gene transcription, it was hypothesized that increased testicular tissue ischemia and hypoxia damage to the basement membrane of endothelial and sertoli cells in the seminiferous tubules may lead to the destruction of the blood-testis barrier, activating autoimmune reaction to produce AsAbs and result in infertility by direct interaction with sperm or indirect change to the local microenvironment.

The vas deferens is the only channel for mature sperm to be transported out of the epididymis (26); changes to the inner environment results in infertility. In this study, examination of the vas deferens showed that the cross-sectional area of the PP and UP groups were significantly reduced with sparse mucosal folds 90 days after surgery. In the e-PTFE group, no significant changes were observed in the vas deferens compared with the $\mathrm{NC}$ and FO groups. This may be due to the smooth surface and 
anti-adhesion nature of e-PTFE mesh, which exhibited protective effects between the vas deferens and spermatic vessels. It has been reported that inguinal hernia tension-free repair can lead to sperm granuloma (17); however, this phenomenon was not observed in our experiment.

In conclusion, in this study $>50 \%$ of mesh adherence to the spermatic cord in the PP and UP groups was identified, while no adhesion or mild adhesion was observed in the NC, FO and e-PTFE groups. In the UP and PP groups, marked congestion of necrotic tissue in the seminiferous tubule cavity, a significant reduction of grade $a+b$ sperm percentage and a considerable statistical increase in the mean level of AsAbs and HIF- $\alpha$. By contrast, the e-PTFE mesh demonstrated only marginal affects on the reproductive function of rats. Thus, it was concluded that e-PTFE mesh had less impact on the reproductive function compared with that of the PP and UP meshes. Therefore, e-PTFE mesh is more suitable for tension-free hernioplasty and should be selected for clinical application in patients with inguinal hernia.

\section{References}

1. Eklund A,Carlsson P, Rosenblad A, et al: Long-term cost-minimization analysis comparing laparoscopic with open (Lichtenstein) inguinal hernia repair. Br J Surg 97: 765-771, 2010.

2. López Cano M, Armengol Carrasco M, Quiles Pérez MT and Arbós Vía MA: Biological implants in abdominal wall hernia surgery. Cir Esp 91: 217-223, 2013 (In Spanish).

3. Yazdankhah Kenary A, Afshin SN, Ahmadi Amoli H, et al: Randomized clinical trial comparing lightweight mesh with heavyweight mesh for primary inguinal hernia repair. Hernia 17: 471-477, 2013.

4. Nathan JD and Pappas TN: Inguinal hernia: an old condition with new solutions. Ann Surg 238: S148-S157, 2003.

5. Birch C and Fynes MM: The role of synthetic and biological prostheses in reconstructive pelvic floor surgery. Curr Opin Obstet Gynecol 14: 527-535, 2002.

6. Shin D, Lipshultz LI, Goldstein M, et al: Herniorrhaphy with polypropylene mesh causing inguinal vasal obstruction: a preventable cause of obstructive azoospermia. Ann Surg 241: 553-558, 2005.

7. Suradom C and Palaphun J: The usage of two umbrella made-mesh plugs in herniorrhaphy: comparative study with Bassini and Lichtenstein method. J Med Assoc Thai 94: 1373-1379, 2011.

8. Kogan BA: Communicating hydrocele/hernia repair in children. BJU Int 100: 703-714, 2007.

9. Peiper C, Junge K, Klinge U, Strehlau E, Ottinger A and Schumpelick V: Is there a risk of infertility after inguinal mesh repair? Experimental studies in the pig and the rabbit. Hernia 10: $7-12,2006$.
10. Aydede H, Erhan Y, Sakarya A, Kara E, Ilkgül O and Can M: Effect of mesh and its localisation on testicular flow and spermatogenesis in patients with groin hernia. Acta Chir Belg 103: 607-610, 2003.

11. Goldenberg A and Paula JF: Effects of the polypropylene mesh implanted through inguinotomy in the spermatic funiculus, epididium and testis of dogs. Acta Cir Bras 20: 461-467, 2005.

12. Kolbe $\mathrm{T}$ and Lechner W: Influence of hernioplastic implants on male fertility in rats. J Biomed Mater Res B Appl Biomater 81: 435-440, 2007.

13. Peiper C, Junge K, Bühner A, Bassalay P and Schumpelick V: Load on the inguinal region under standard conditions in pigs. Eur J Surg 167: 356-361, 2001.

14. LeBlanc KA, Booth WV, Whitaker JM and Baker D: In vivo study of meshes implanted over the inguinal ring and external iliac vessels in uncastrated pigs. Surg Endosc 12: 247-251, 1998.

15. Fernández-Braña M: Hypoxia: a therapeutic target. Clin Transl Oncol 7: 475-476, 2005 (In Spanish).

16. Anderson DJ and Alexander NJ: Consequences of autoimmunity to sperm antigens in vasectomized men. Clin Obstet Gynaecol 6: 425-442, 1979.

17. Silich RC and McSherry CK: Spermatic granuloma. An uncommon complication of the tension-free hernia repair. Surg Endosc 10: 537-539, 1996.

18. Walker AP, Henderson J and Condon RE: Double-layer protheses for repair of abdominal wall defects in rabbit model. J Surg Res 55: 32-37, 1993.

19. Johnsen SG: Testicular biopsy score count - a method for registration of spermatogenesis in human testes: normal values and results in 335 hypogonadal males. Hormones 1: $2-25,1970$.

20. Xue J, Yang J, Yan J, et al: Abnormalities of the testes and semen parameters in clinical varicocele. Nan Fang Yi Ke Da Xue Xue Bao 32: 439-442, 2012.

21. Zendejas B, Ramirez T, Jones T, et al: Incidence of inguinal hernia repairs in Olmsted County, MN: a population-based study. Ann Surg 257: 520-526, 2013.

22. Bierca J, Kosim A, Kołodziejczak M, Zmora J and Kultys E: Effectiveness of Lichtenstein repairs in planned treatment of giant inguinal hernia - own experience. Wideochir Inne Tech Malo Inwazyjne 8: 36-42, 2013.

23. Pielaciński K, Szczepanik AB, Misiak A and Wróblewski T: Randomized clinical trial comparing inguinal hernia repair with Lichtenstein technique using non-absorbable or partially absorbable mesh. Preliminary report. Wideochir Inne Tech Malo Inwazyjne 6: 190-206, 2011.

24. Wang WJ, Chen JZ, Fang Q, Li JF, Jin PF and Li ZT: Comparison of the effects of laparoscopic hernia repair and lichtenstein tension-free hernia repair. J Laparoendosc Adv Surg Tech A 23 . 301-305, 2013.

25. Junge K, Binnebösel M, Kauffmann C, et al: Damage to the spermatic cord by the Lichtenstein and TAPP procedures in a pig model. Surg Endosc 25: 146-152, 2011.

26. Da Silva N, Silberstein C, Beaulieu V, et al: Postnatal expression of aquaporins in epithelial cells of the rat epididymis. Biol Reprod 74: 427-438, 2006. 